\title{
A aporía democrática: o caminho de Prometeu
}

\author{
The democratic aporia: Prometheus' Path
}

\section{Luiz Maurício Bentim da Rocha Menezes ${ }^{1}$}

1 Doutor em Filosofia (UFRJ). Professor de Filosofia, Ética e Política no Instituto Federal de Educação, Ciência e Tecnologia do Triângulo Mineiro, Brasil.

E-mail: Imbrmenezes@yahoo.com.br Orcid: http://lattes.cnpq.br/5932586465926963

RESUMO: Desde a antiguidade, a democracia apresenta-se como uma espécie de aporía política, pois ao mesmo tempo em que permite a liberdade a todos os cidadãos, ela também nos traz a problemática do conhecimento para governar. Afinal, todos os cidadãos são tão aptos a governar como o são para votar ou haveria uma autoridade epistêmica para se julgar as decisões políticas? Segundo o mito de Prometeu, há uma aporia sobre a humanidade que será solucionada através do roubo do fogo e da arte (téchne) divinos. No caso do mito, a aporía se resolve no ensino das artes aos homens, sendo cada uma delas específica a cada tipo humano. A exceção se dá com a arte política, que é distribuída igualitariamente por Zeus. Dessa forma, todos os humanos estariam aptos a deliberar sobre a política. Nosso intuito com este trabalho é fazer uma analogia entre o mito de Prometeu e a democracia contemporânea, fazendo o contraste entre liberdade e autoridade, de maneira que possamos identificar problemas e propor soluções para essa forma de governo.

Palavras-chave: Filosofia Política; História Política; Mito de Prometeu; Democracia; Filosofia da Tecnologia.

ABSTRACT: Since Ancient times democracy is presented as some sort of political aporia, as it grants freedom to all citizens, nevertheless, presenting us with the matter of knowledge to rule. After all, is the body citizen capable of ruling as it is of voting, or would there be an epistemic authority to judge political decisions? According to the myth of Prometheus there is an aporia about humanity which is solved through the theft of the divine, fire and arts (techne). As for the myth, the aporia is solved when men are taught in the arts, being each of these specific to every human type. The exception happens with the political art, which is equally distributed by Zeus. Thusly, all human beings would be capable of deliberating on politics. Our aim with this paper is to make an analogy between the Prometheus' myth and the contemporary democracy, establishing the contrast between freedom and authority, objecting the identification of problems, as well as offering solutions for this kind of government.

Keywords: Political Philosophy; Political History; Prometheus' Myth; Democracy; Philosophy of technology.

\section{Introdução}

A democracia se tornou a forma de governo predominante nos governos ocidentais hodiernos. Um dos antigos lemas defendidos pelos democratas é o poder diretamente nas mãos do povo, porém, nos tempos modernos, a democracia direta acabou por se tornar inviável e foi substituída pela democracia representativa, em que o povo elege os seus representantes para que estes governem no lugar daqueles. Isso acabou por trazer prejuízos à democracia, pois viabilizou a constituição de oligarquias no poder disfarçadas pelas instituições democráticas. O que nos leva à temática desse trabalho que é a comparação do go- 
verno democrático entre antigos e modernos, analisando seus pressupostos e tendo como objetivo levantar a discussão sobre o problema democrático atual.

Desde a antiguidade, a democracia apresenta-se como uma espécie de aporía política, pois ao mesmo tempo em que permite a liberdade a todos os cidadãos, ela também nos traz a problemática do conhecimento para governar. Afinal, todos os cidadãos são tão aptos a governar como o são para votar ou haveria uma autoridade epistêmica para se julgar as decisões políticas? Em outras palavras, o ato de governar exige conhecimento ou pode ser feito por qualquer um? Segundo o mito de Prometeu, posto pelo personagem Protágoras, há uma aporía sobre a humanidade que será solucionada através do roubo do fogo e da arte (téchne) divinos. No caso do mito, a aporía se resolve no ensino das artes aos homens, sendo cada uma delas específica a cada tipo humano. A exceção se dá com a arte política, que é distribuída igualitariamente por Zeus. Dessa forma, todos os humanos estariam aptos a deliberar sobre a política. Nosso intuito com este trabalho é fazer uma analogia entre o mito de Prometeu e a democracia contemporânea, fazendo o contraste entre liberdade e autoridade, de maneira que possamos identificar problemas e propor soluções para essa forma de governo.

\section{0 mito de Prometeu}

No Protágoras de Platão ${ }^{1}$, o personagem Protágoras irá iniciar a sua exposição através do mito de Prometeu (Prot., 320d1-322d5). Segundo ele, no momento em que os seres estavam para surgir no mundo, Zeus determinou que Prometeu e Epimeteu distribuíssem as dádivas a todas as criaturas. Epimeteu disse a Prometeu que ele mesmo faria a tarefa e que depois o irmão avaliaria o seu trabalho. Após o fim do trabalho de Epimeteu, Prometeu pode perceber que ele havia esquecido de uma das criaturas: o humano. Diante da aporia posta pelo irmão, Prometeu resolve ir até a morada dos deuses para roubar o fogo e as artes

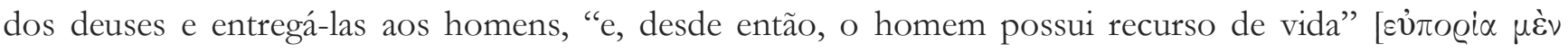

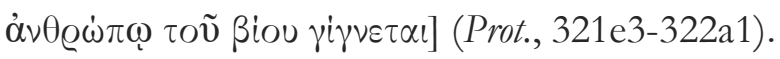

A palavra aporía pode ser melhor entendida se for dividida no prefixo de negação "a" e a palavra "póros" que significa passagem, caminho ou recurso. Aporía seria, portanto, "sem passagem" ou "sem recurso". A aporia é um elemento de perplexidade que impulsiona a filosofia a buscar soluções para as suas questões, sendo um desafio imposto ao filósofo. No caso desse mito, a aporía se resolve no ensino das téchnai aos homens, o que faz de Prometeu um filósofo divino capaz de abrir a passagem, dar o recurso, o póros, à humanidade, mesmo que sua atitude tenha o condenado aos grilhões inquebrantáveis de Hefesto.

Prometeu, dessa forma, pode ser reconhecido como o primeiro humanista, pois se condenou para salvar a humanidade de forma irrestrita. A filosofia, já diziam os antigos, começa com o espanto, com o questionar-se sobre o mundo. Sem questão não há filosofia e toda questão leva a um impasse a ser resolvido. O homem que filosofa é um homem que se move na dificuldade de resolver uma questão, de pensar sobre os caminhos possíveis a serem percorridos no intuito de se encontrar uma resposta adequada para o impasse. No entanto, o filósofo é somente aquele que se adianta sobre o problema ou aquele que se dedica a resolver o problema, pois a aporia pertence ao próprio sentido do humano. Prometeu através da sua ação para com os homens, vem aproximar a humanidade da dádiva divina e nos permitir a abertura do cami-

\footnotetext{
1 Para a tradução, utilizaremos o texto de Daniel R. N. Lopes, Protágoras. (São Paulo: Perspectiva; FAPESP, 2017). Demais referências ao 'Protágoras' serão abreviadas por Prot. indicando-se em seguida a numeração. Para o original grego em todo o trabalho, utilizaremos o texto estabelecido por John Burnet, Platonis Opera, t. 3 (Oxford: Clarendon, 1968).
} 
nho. No entanto, ainda faltava aos homens a arte política:

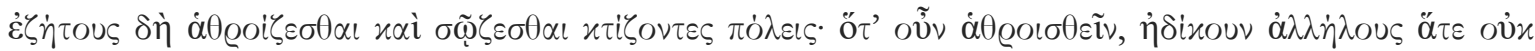

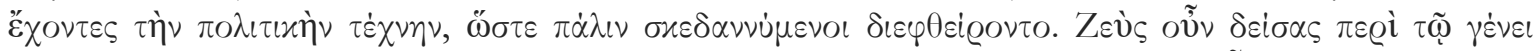

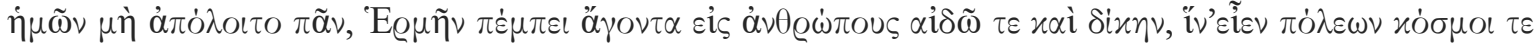

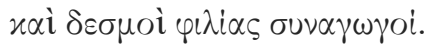

Procuravam, então, reunir-se para se preservar, fundando cidades; mas, quando se reuniam, injustiçavam-se mutuamente, uma vez desprovidos da arte politica. Por conseguinte, dispersavam-se novamente e eram aniquilados. Zeus, pois, temeroso do total perecimento de nossa geração enviou Hermes aos homens portando justiça e pudor, para que houvesse ordem nas cidades e vínculos estreitos de amizade. (Prot., 322b6-c3)

Ao contrário das outras artes, que tem um conhecimento especializado, Zeus determinou que todos os humanos compartilhassem da justiça e do pudor permitindo, dessa forma, que todos os homens estivessem aptos a desempenhar a arte política. O mito de Prometeu tem uma importância explicativa, isto é, através de um recurso imagético, Protágoras pretende explicar o motivo pelo qual a téchne política é diferente das demais téchnai.

Similarmente pode-se dizer que o mito de Protágoras não poderia servir a um propósito sério se fosse apenas para dar uma descrição da falta de senso de justiça em todos os homens. Desse modo, nenhum homem existe. Mas como uma ideia concebida no limite da imaginação, ele [o mito] opera como uma norma negativa: qualquer ação leva na direção dessa norma ou o estado descrito no mito é nessa medida ruim; qualquer ação que afaste isso é, ipso facto, boa. (WOLZ, 1963, p. 223)

A analogia proporcionada pelo mito permite a Protágoras argumentar por uma diferença específica presente na arte política, de maneira que todos teriam a capacidade para fazer política, sendo que o aprimoramento dessa arte seria feito através do ensino. A justiça e o pudor aparecem em germe nos seres humanos, pois foram igualmente distribuídas por Zeus. Será através do aprimoramento da justiça que os humanos poderão construir cidades e seguir um determinado regime normativo. No caso específico da democracia, o poder político pertence a todos os cidadãos, isso estaria coerente com a visão protagórica do mito descrito. Podemos levantar aqui como contraste para a temática o fato de não se precisar de um conhecimento específico para a política, de maneira que todos estão aptos ao seu exercício na democracia. Isso vai em oposição direta a um governo dos melhores composto por aqueles que têm um conhecimento específico para governar, conforme nós podemos ver desde o princípio da República de Platão². No Livro I, podemos ver que a defesa de Trasímaco de uma téchne do governo que tem, no seu saber próprio, a sua infalibilidade é o prenúncio de que o governo também participa de um tipo de conhecimento específico que lhe dá o estatuto de arte. Será através das colocações de Trasímaco que, primeiramente, se fará a relação entre justiça, cidade e governo e, também, teremos o estabelecimento de uma arte do governo, arte essa que determinaria o justo dentro da cidade. Essa visão se opõe diretamente ao governo democrático em que a arte política se faz pelo conjunto de cidadãos independente do conhecimento que esses têm da política em geral. O ambiente democrático seria, portanto, aquele em que há uma capacidade geral dos cidadãos para a feitura da política diretamente, de maneira, que todos estão aptos a opinar e exercer o seu

2 Para a tradução, utilizaremos o texto de Maria Helena da Rocha Pereira, A República (Lisboa: Fundação Calouste Gulbenkian, 2001). Demais referências à 'República' serão abreviadas por Rep. indicando-se em seguida a numeração. Para o original grego em todo o trabalho, utilizaremos o texto estabelecido por S. R. Slings, Platonis Rempvblicam (Oxford: Oxford University Press, 2003). 
papel político na cidade.

\section{A democracia moderna}

Em um discurso pronunciado no Athénée Royal de Paris em 1819, Benjamin Constant irá apresentar dois sentidos de liberdade que ficaram consagrados pela modernidade. A primeira seria a liberdade política, desempenhada dentro do âmbito da pólis e na tomada de decisões da cidade como um cidadão que tem não só uma capacidade para decidir, mas também um poder para agir dentro da cidade. A segunda seria a liberdade individual, que seria composta pelas garantias individuais que cada indivíduo tem para fazer o que bem entende dentro dos limites constitucionais permitidos. Separando a ideia de liberdade entre os antigos e os modernos, Constant irá defender que

A liberdade individual, repito, é a verdadeira liberdade moderna. A liberdade política é a sua garantia e é, portanto, indispensável. Mas pedir aos povos de hoje para sacrificar, como os de antigamente, a totalidade de sua liberdade individual à liberdade política é o meio mais seguro de afastá-los da primeira, com a consequência de que, feito isso, a segunda não tardará a lhe ser arrebatada. (CONSTANT, 1985, p. 5)

Benjamin Constant pode ser considerado como um dos pensadores basilares do liberalismo. Marcado pelas contradições de seu tempo, Constant soube enfrentar com afinco as problemáticas posteriores à Revolução Francesa. Se observarmos bem isso, podemos entender o tipo de pensamento que se pretende fundamentar com o texto dele aqui apresentado. A liberdade política é sacrificada em sua capacidade de ação pela primazia da liberdade individual, mas isso não significa o seu abandono, pois a liberdade política passa a ser a garantia para a liberdade individual. Dessa forma, o indivíduo moderno se tornou alguém que preza em primeiro lugar a sua própria liberdade para fazer o que bem quer em âmbito privado, abdicando, inclusive, do direito de atuar politicamente. Gradualmente esse tipo de pensamento levará a alienação das massas da sua capacidade de governar, deixando a cargo de outros esse poder. No Brasil, o pensamento de Constant foi bastante influente na formação de nossa primeira constituição federal, a Constituição Brasileira de 1824, que formalizou o Império de D. Pedro I. É oriundo do arcabouço teórico de Constant a previsão constitucional de um Poder Moderador (ALVES, 2008, p. 70).

Um outro ponto a ser discutido nas democracias modernas é a questão da igualdade. Ponto de dificuldade e, talvez, o mais controverso, já que para alguns a igualdade em sua totalidade implica em menos liberdade, mas para outros, o próprio sentido de democracia já indica um governo de iguais. Rancière, em seu estudo sobre a democracia, irá retomar alguns dos pontos da democracia originária grega, como o sorteio, a anarquia e o acaso.

Democracia quer dizer, em primeiro lugar, o seguinte: um "governo" anárquico, fundamentado em nada mais do que na ausência de qualquer título para governar. Mas há várias maneiras de tratar esse paradoxo. Podemos simplesmente excluir o título democrático, já que se trata da contradição de qualquer título para governar. Também podemos negar que o acaso seja o princípio da democracia, separar democracia e sorteio. Assim fazem os modernos, especialistas, como vimos, em jogar alternadamente com a diferença ou com a semelhança dos tempos. O sorteio, segundo eles, convinha aos tempos antigos e aos vilarejos economicamente pouco desenvolvidos. Como nossas sociedades modernas, feitas de tantas engrenagens delicadamente encaixadas, poderiam ser governadas por homens escolhidos por sorteio, ignorando a ciência desses frágeis equilíbrios? Encontramos para a democracia princípios e meios mais apropriados: a representação do povo soberano por seus eleitos, a simbiose entre a elite 
dos eleitos do povo e a elite daqueles que nossas escolas formaram no conhecimento do funcionamento das sociedades. (RANCIÈRE, 2014, p. 57)

Rancière em seu livro "O ódio à democracia" critica duramente todo o tipo de pensamento antidemocrático que tenta desmerecer o governo democrático em seu sentido mais pleno. A democracia nasceu para ser o governo do povo pelo povo, o que implica em todo tipo de contraposição que isso possa significar. Com isso, Rancière dialoga muito com Platão e seu filósofo governante.

[O] procedimento democrático do sorteio está de acordo com o princípio do poder dos sábios em um ponto essencial: o bom governo é o governo daqueles que não desejam governar. Se há uma categoria que deve ser excluída da lista dos que são aptos a governar, é a dos que intrigam para obter o poder.

$[\ldots]$

O filósofo-rei tem ao menos um ponto em comum com o povo-rei: é necessário que o acaso divino o faça rei, sem que ele o tenha desejado.

Não existe governo justo sem participação do acaso, isto é, sem participação daquilo que contradiz a identificação do exercício do governo com o exercício de um poder desejado e conquistado. Esse é o princípio paradoxal que se coloca onde o princípio do governo se desliga daquele das diferenças naturais e sociais, isto é, onde há política. E este é o desafio da discussão platônica sobre o "governo do mais forte". (RANCIĖRE, 2014, p. 59)

De maneira suscinta, de modo que não ultrapassemos o escopo deste trabalho, há dois problemas básicos para o estabelecimento do governo do filósofo na República:

1) os filósofos não desejam governar.

2) os filósofos não são escolhidos pelo povo.

O primeiro problema é um problema de justiça: os filósofos devem governar, pois são os melhores para governar a cidade e isso é o justo a ser feito. O segundo problema é um problema de persuasão, que só pode ser resolvido pelo acaso. Ambos os problemas têm uma parte imagética exposta na obra para explicá-los. Para o primeiro, temos a "imagem da Caverna" (Rep., 514a et seq), já para o segundo, temos a “imagem da Nau do Estado” (Rep., 488a7-489a2). Atentemo-nos para a segunda imagem, por ser a mais afim com o presente artigo, deixando para um trabalho posterior a análise da Caverna. $\mathrm{Na}$ imagem da nau, podemos ver a dinâmica que se apresenta em uma cidade democrática e como esta exclui o filósofo do governo. Para Keyt, "a autoridade dos governantes da Kallípolis deriva do seu conhecimento mais do que do seu governo [...]; mas o símile [da nau] implica o reverso, que a sua autoridade pode derivar do dêmos" (KEYT, 2006, p. 207). Isso leva ao desenvolvimento do problema de como legitimar o poder do filósofo sobre o dêmos, fazendo com que o dêmos opte pelo governo do filósofo e obedeça às suas recomendações (Cf. Rep., 489b-c). Para responder ao problema, precisamos retomar a analogia tendo a coerção (anánke) como o recorte principal, coisa que comumente fica de fora das interpretações padrões. A anánke é o que distingue o verdadeiro governante daquele que não é, mas isso não garante ainda o seu governo, pois é preciso que o povo seja persuadido e opte pelo seu governo sem que o filósofo clame por isso. Dessa forma, anánke aponta a um requisito para o conhecimento (epistéme), como condições a serem cumpridas, porém a própria epistéme não é garantia para o governo do filósofo. Caso o filósofo desejasse o governo, ele seria tomado como os marinheiros na disputa pelo poder. Entretanto, o fato, do filósofo recusar o governo e, mesmo assim, ser obrigado por coerção a governar é peça fundamental para o bom governo do filósofo, sem o qual ele não poderia ser o verdadeiro governante.

$\mathrm{Na}$ República, a anánke exerce de alguma maneira o seu poder sobre aquele que detém a natureza fi- 


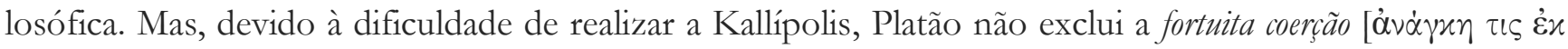

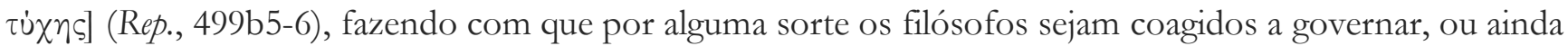

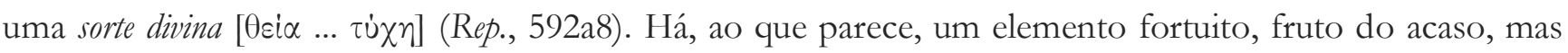
com uma força capaz de levar o filósofo ao governo. O que Rancière parece indicar em seu livro é que há uma força legítima no acaso para se legitimar um governo político. Mais especificamente, a democracia seria o melhor governo para se testar essa força e eliminar as mazelas viciosas da política temporal, já que levaria o próprio povo a assumir o governo.

Miguel aponta que há pensadores sérios que defendem uma "teoria das elites", alegando uma impossibilidade da existência das democracias. "Os fundadores dessa corrente, Mosca, Pareto e Michels, não escondiam sua oposição aos movimentos democráticos e socialistas presentes na virada do século XIX para o XX" (MIGUEL, 2002, p. 485). Visto isso, pode-se falar em uma corrente elitista que se dirige contra o governo do povo por julgar que as massas não tem como governar a si mesmas e devem ser governadas por pessoas melhores.

No seu sentido corrente, o elitismo pode ser descrito como a crença de que a igualdade social é impossível, de que sempre haverá um grupo naturalmente mais capacitado que deterá os cargos de poder. Não se trata de ideia nova: o sonho de Platão na República, com a divisão de castas (de acordo com a capacidade de cada um), reflete essa visão, bem como a crença de Aristóteles na existência de "escravos por natureza". Apalavra "natureza" é crucial: para o elitismo, a desigualdade é um fato natural. Isto está na raiz da atração que o pensamento elitista tem sobre aqueles que ocupam posições de elite. Em vez de estarem nessas posições como fruto do acaso, de contingências ligadas à estrutura da sociedade, seriam recompensados por seus méritos intrínsecos. (MIGUEL, 2002, p. 486-487)

Isso aponta para o contraponto que estamos verificando nesse trabalho sobre a defesa de um governo de todos pelas vias democráticas e por um governo da elite que tem um saber para gerenciar e manter o poder sobre as massas. Podemos fazer um equivalente contemporâneo dessa visão quando um povo opta democraticamente por um governo fascista, isto é, um governo que exalta o nacionalismo acima de todos, demonstrando-se intolerante a tudo que possa ser diferente aos seus próprios conceitos. O fascismo é a morte do outro e a predominância do mesmo sobre tudo que há. Apesar de ser historicamente um movimento político-ideológico do início do século XX, o fascismo tem uma capacidade impressionante de se renovar, sendo capaz de se mesclar às demandas da elite de um país em detrimento do povo. Para Foucault, as massas no momento do fascismo desejam que alguns exerçam o poder, alguns que, no entanto, não se confundem com elas, visto que o poder se exercerá sobre elas e em detrimento delas, até a morte, o sacrifício e o massacre delas; e, no entanto, elas desejam este poder, desejam que esse poder seja exercido.

\section{Conclusão e Aporía}

Tentamos com esse trabalho apresentar uma leitura da democracia fazendo um paralelo entre antigos e modernos. Para isso, nos centramos na posição de Platão através das obras Protágoras e República e trazendo-as para uma discussão contemporânea através de uma análise crítica de seus elementos.

Gostaríamos de encerrar nosso trabalho falando minimamente de Brasil e o futuro da política brasileira. O Brasil nunca vai avançar como nação enquanto não avançar em seu problema de desigualdade social. Para isso é preciso resolver a questão de terras, redistribuir renda com a taxação de grandes fortunas e bancos privados, estimular o crescimento das indústrias nacionais, além de melhorar o acesso ao crédito 
à classe mais baixa da população e investir assiduamente nos programas sociais. A concentração de renda é um total descaso com os problemas reais do país e agride diretamente os princípios democráticos. Em seu ensaio sobre a cidadania no Brasil, José Murilo de Carvalho apresenta o longo caminho percorrido e o aquele que ainda falta percorrer.

Diante dessas mudanças, países como o Brasil se veem frente a uma ironia. Tendo corrido atrás de uma noção e uma prática de cidadania geradas no Ocidente, e tendo conseguido alguns êxitos em sua busca, veem-se diante de um cenário internacional que desafia essa noção e essa prática. Gera-se um sentimento de perplexidade e frustração. A pergunta a se fazer, então, é como enfrentar o novo desafio. (CARVALHO, 2012, p. 226)

Estamos diante de um novo desafio. Para que haja o progresso da democracia, é preciso buscar soluções que privilegiem a construção de novos espaços para a deliberação e discussão (BEÇAK, 2013). Cidadãos que deliberam podem neutralizar a manipulação da elite (DRYZEK et al., 2019) e, dessa forma, constituir um espaço comum para o desempenho de uma política deliberativa e cidadã, o que poderíamos chamar de boa política. No entanto, ao que tudo indica, continuamos na mesma posição de Prometeu diante da humanidade: sem conseguir ainda resolver sua aporía. São aportes desse tipo que devem ser melhor estudados teoricamente para um desenvolvimento de maiores resultados no futuro, pois, em pleno século XXI, continuamos no âmbito dialético da contradição entre um governo autoritário e um governo democrático.

\section{Referências}

ALVES, C. F. A influência do pensamento liberal de Benjamin Constant na formação do Estado Imperial Brasileiro. Revista de Informação Legislativa, v. 45, n. 180, p. 65-75, 2008.

BEÇAK, R. Democracia moderna: sua evolução e o papel da deliberação. Revista de Informação Legislativa, v. 50, n. 199, p. 7-23, 2013.

BOBBIO, N. Estado, Governo, Sociedade. Para uma teoria geral da política. São Paulo: Paz e Terra, 2012.

BOBBIO, N. O futuro da democracia. São Paulo: Paz e Terra, 2000.

CARVALHO, J. M. Cidadania no Brasil. O longo caminho. Rio de Janeiro: Civilização Brasileira, 2012.

CONSTANT, B. Da liberdade dos antigos comparada à dos modernos. Revista Filosofia Política, $\mathrm{n}$. 2, p. 1-7, 1985.

DRYZEK, J. S. et al. The crisis of democracy and the science of deliberation. Science, v. 363, p. 1144-1146, 2019.

HOBBES, T. Leviatã. Organizado por Richard Tuck. Tradução de João Paulo Monteiro e Maria Beatriz Nizza da Silva. São Paulo: Martins Fontes, 2008.

GONZALEZ, F. J.; DESTRÉE, P.; COLlOBERT, C. Plato and Myth. Leiden; Boston: Brill, 2012.

KEYT, D. Plato and the Ship of the State. In: SANTAS, G. (Ed.). The Blackwell Guide to Plato's Republic. Malden: Blackwell Publishing Ltd, 2006, p. 189-213.

LUCHI, J. P. Para uma teoria deliberativa da democracia. Revista de Informação Legislativa, v. 43, 
n. 172, p. 73-83, 2006.

MENEZES, L. M. B. R. O problema da filosofia política. Investigação Filosófica, v. 10, n. 1, p. 141152, 2019.

MIGUEL, L. F. A Democracia Domesticada: Bases Antidemocráticas do Pensamento Democrático Contemporâneo. DADOS - Revista de Ciências Sociais, v. 45, n. 3, p. 483 a 511, 2002.

PLATÃO. A República. Tradução e organização de J. Guinsburg. São Paulo: Perspectiva, 2006.

PLATÃO. Protágoras. Tradução, estudo introdutório, comentários e notas de Daniel R. N. Lopes. São Paulo: Perspectiva; FAPESP, 2017.

RANCIĖRE, J. O ódio à democracia. Tradução de Mariana Echalar. São Paulo: Boitempo, 2014.

RIBEIRO, R. J. A Boa Política. São Paulo: Companhia das Letras, 2017.

ROUSSEAU, J.-J. Do Contrato Social. Tradução de Lourdes Santos Machado. São Paulo: Abril Cultural, 1978. (Coleção Os Pensadores)

ROUSSEAU, J.-J. Discurso sobre a Origem e os Fundamentos da Desigualdade entre os Homens. Tradução de Maria Ermantina Galvão. São Paulo: Martins Fontes, 2002.

SILVA, E. M. O Estado Democrático de Direito. Revista de Informação Legislativa, v. 42, n. 167, p. 213-230, 2005.

SLINGS, S. R. Platonis Rempvblicam, recognovit brevique adnotatione critica instrvxit: S. R. Slings. Oxford: Oxford University Press, 2003.

STRAUSS, L. What is Political Philosophy? The Journal of Politics, v. 19, 1957, p. 343-368.

STRAUSS, L. The City and Man. Chicago; London: The University of Chicago Press, 1964.

VAN RIEL, G. Religion and Morality. Elements of Plato's Anthropology in the Myth of Prometheus (Protagoras, 320d-322d). In: GONZALEZ, F. J.; DESTRÉE, P.; COLLOBERT, C. Plato and Myth. Leiden; Boston: Brill, 2012, p. 145-164.

WOLZ, H. G. The Protagoras Myth and the Philosopher-Kings. The Review of Metaphysics, v. 17, n. 2, p. 214-234, 1963.

WEST, M. L. lambi et Elegi Graeci. Ante Alexandrum Cantati. (Editio Altera). Edidit M. L. West. Oxford: Oxford University Press, 1971.

Artigo recebido em: 18 de fevereiro de 2020

Artigo aceito em: 21 de fevereiro de 2020 